\title{
Small Cell Carcinoma of Ethmoid Sinus
}

\author{
P. Adhikari, ${ }^{1}$ R. Bhatta, ${ }^{1}$ B. Pradhan, ${ }^{1}$ N. Thapa, ${ }^{1}$ R. Bhandari, ${ }^{1}$ R. Karki, ${ }^{1}$ A. Shrestha, ${ }^{2}$ G. Sayami. ${ }^{2}$ \\ ${ }^{1}$ Department of ENT and Head and Neck Surgery, TU Teaching Hospital; ${ }^{2}$ Department of Pathology, TU Teaching Hospital, \\ Kathmandu, Nepal.
}

Correspondence to : Dr. Prakash Adhikari, GMS Memorial Academy of ENT and Head and Neck Studies, TU Teaching Hospital, Kathmandu, Nepal.

Email:prakash_ooz@hotmail.com

\begin{abstract}
Extrapulmonary small cell carcinoma is a rare entity. Here, we report a case of small cell carcinoma of left ethmoid sinus, in a 32 years old female. She underwent left medial maxillectomy and excision of the mass via lateral rhinotomy approach with post operative chemoradiation.
\end{abstract}

Keywords: Ethmoid Sinus, lateral rhinotomy, maxillectomy, small cell carcinoma.

\section{Introduction}

Since its initial description in 1930, extrapulmonary small cell carcinoma (SCC) is recognized as a clinico-pathological entity distinct from small cell carcinoma of the lung. ${ }^{1}$ vast majority of small cell carcinoma develops from the lung, but only $2.5 \%$ of SCC is present at extra-pulmonary sites. ${ }^{2}$ It includes head and neck, pancreas, cervix, kidney, urinary tract, prostate and esophagus. ${ }^{3}$ In general, the clinical course of this tumour is very aggressive and often recurs after treatment. ${ }^{1}$ Multimodality therapy is the best therapeutic option of the disease.

\section{Case report}

A 32 years old female admitted, in the department of ENT and Head and Neck Surgery, TU Teaching Hospital, Kathmandu, with the complains of gradually progressive left nasal obstruction and intermittent bleeding from left nasal cavity for two months. On examination her general condition was fair. Anterior rhinoscopy revealed firm, fleshy mass on left nasal cavity which bleeds on touch while on posterior rhinoscopy also revealed similar type of mass on left choana and extending its part in right choana (Fig. 1). Her systemic examination was normal. On biopsy of the mass, small cell carcinoma was revealed. CT Scan Nose and paranasal sinuses showed contrast enhancing non homogenous mass involving left nasal cavity, choana, maxillary sinus, ethmoid and frontal sinus with erosion of medial wall of maxillary sinus and lamina papyracea (Fig. 2, 3). Metastatic work up was done and it was ruled out.

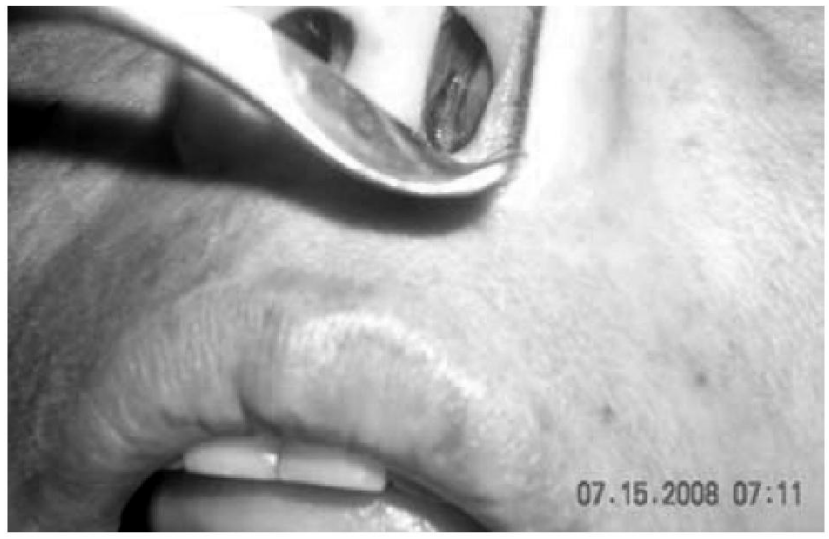

Fig. 1: Anterior rhinoscopy showing fleshy mass on left nasal cavity.

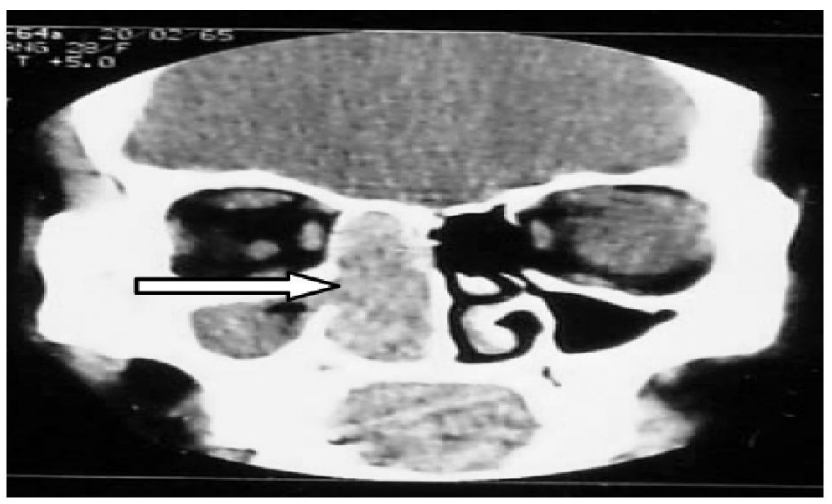

Fig. 2: CT Scan nose and paranasal sinus coronal cut showing non homogenous soft tissue mass involving left nasal cavity and maxillary sinus. 


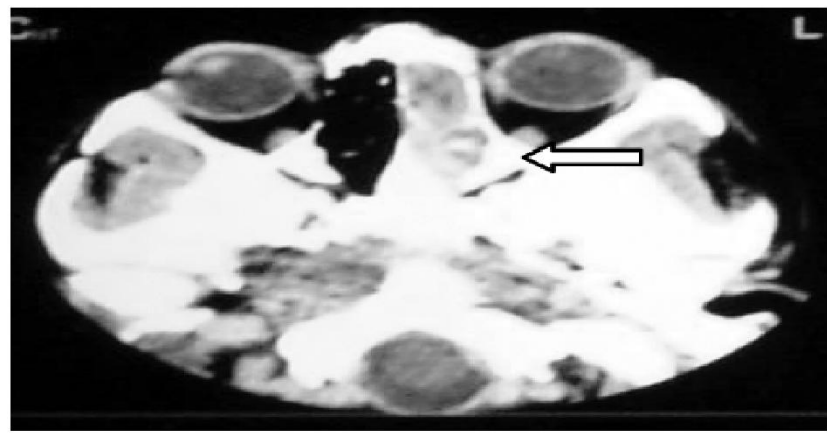

Fig. 3: CT Scan nose and paranasal sinus axial cut showing non homogenous soft tissue mass involving left nasal cavity.

Patient underwent left medial maxillectomy and excision of the mass via lateral rhinotomy approach. Per-operative findings include brownish colored, firm, friable mass, in left anterior ethmoid, left nasal cavity and nasopharynx. Medial wall of maxilla was eroded with thick tenacious glue in maxillary antrum, posterior ethmoid and frontal sinus on left side. Left sphenoid sinus was normal and orbital floor and orbital periosteum was intact. Histopathologial examination showed small cell carcinoma involving left maxilla, ethmoid and nasal cavity with extensive lymphovascular invasions. Post-operative period was uneventful. Thus, final diagnosis of small cell carcinoma of left ethmoid sinus with extension to left nasal cavity and left medial wall of maxillary sinus and nasopharynx. (T3NOMx). Patient was sent for chemoradiation and she is alright when she presented on follow up after 3 months of surgery.

\section{Discussion}

Extrapulmonary small cell carcinoma is a rare entity. Here we report these rare malignancies which arise from the ethmoid sinus and extending to left nasal cavity and medial wall of maxillary sinus and nasopharynx. Extrapulmonary small cell carcinoma is generally aggressive and often recurrent. ${ }^{3}$ When a diagnosis of small cell carcinoma in extrapulmonary site is made, a thorough search evaluation should be done to find out whether the disease is primary or metastasis. In our case, as there was no facility of immunohistochemistry, it was not done.

Histologically small cell carcinoma shows a solid nest of cells separated by connective tissue which features small round to oval shaped hyperchromatic nuclei and scanty cytoplasm. ${ }^{4}$ Demonstration of dense core neurosecretory granules in the cytoplasm of the tumours cells under the electronmicroscope can be of supportive significance when diagnosing SCC. ${ }^{4}$ The immunohistochemical study is important in the differential diagnosis with other malignant entities and it includes lymphoma, rhabdomyosrcoma, undifferentiated nasopharyngeal carcinoma and undifferentiated sinonasal carcinoma. Strongly positive staining for synaptophysin and CD56 can be observed and weak staining for chromogranin A and CA 52/AE-1. ${ }^{5}$

Chemotherapy along with radiotherapy is the main treatment modality of small cell carcinoma in head and neck region. Curative surgery is indicated in case of early stage of the disease. In our case, surgery was done along with postoperative chemoradiation. The response to treatment and median survival in group of patients with these therapies has been disappointing. Chemotherapy or combination therapy has an overall response rate of up to $90 \%$ and complete response rate up to $50 \%$ using combination therapy. The median survival is reported to be from several weeks to 12 months. However patients with local disease alone without extension to adjacent structures or nodal metastases did relatively well, demonstrating a $60 \%$ survival rate at 100 months. ${ }^{1}$

\section{Conclusions}

Small cell carcinoma of nasal cavity is extremely rare tumour. A thorough systemic workup should be done to rule out metastasis if it is present in extrapulmonary sites, even with aggressive treatment with chemoradiation there is a high rate of local recurrence and poor prognosis so that a close long term follow up advised.

\section{References}

1. Galanis F, Frytak S, Llyod RV. Extrapulmonary small cell carcinoma. Cancer 1997;9:1729-36.

2. Henricus FM, Yuonne F. Extrapulmonary small cell carcinoma. South Med J 2005;98:345-9.

3. Renick SC, Ruckdeschel JC. Extrapulmonary and pulmonary small cell carcinoma: tumor biology, therapy and outcome. Med Pediatr Oncol 1992; 20:89-99.

4. Weiss MD, defries Ho, Taxy JB, BraineH. Primary small cell carcinoma of the paranasal sinuses. Arch Otolaryngol 1983;109:341-3.

5. Avitia S, Osborne RF. Blindness: a sequale of sinonasal small cell neuroendocrine carcinoma. Ear Nose Throat J 2004;83:530-2. 